\title{
Isolation of polymorphic microsatellite markers from Przewalskia tangutica (Solanaceae)
}

\author{
Dongshi Wan · Ailan Wang • Guili Wu • \\ Changming Zhao
}

Received: 1 September 2007 / Accepted: 6 September 2007/Published online: 18 September 2007

(C) Springer Science+Business Media B.V. 2007

\begin{abstract}
Microsatellite-containing regions were isolated and characterized in Przewalskia tangutica Maxim (Solanaceae), an endemic and endangered species to the Qinghai-Tibetan Plateau of China. An enrichment protocol yielded 200 positive clones. We designed primers to amplify 29 unique microsatellites, 12 of which amplified cleanly and were polymorphic. A survey of 17 individuals showed that these loci are highly variable with the number of alleles ranging from 3 to 12 , and expected heterozygosity ranged from 0.2929 to 0.4947 . Those markers will be useful for studies of population structure and intraspecific variation in $P$. tangutica.
\end{abstract}

\section{Keywords Przewalskia tangutica.}

Microsatellite markers · Genetic diversity

Przewalskia tangutica, the only species in this monotypic genus of the tribe Hyoscyameae (Solanaceae), is mainly distributed in sandy and gritty grasslands of the QinghaiTibetan Plateau at altitudes ranging from 3,000 to 4,000 m. Because of its medicinal importance (associated with high biologically active nicotine and tropane alkaloid contents) (Pei and Li 1982; Wang et al. 2002), the species has been subjected to extensive collection and the size of most populations has decreased greatly; some have even disappeared (Yang 1991). Except for its phylogenetic and taxonomic relationships (Yang et al. 2002), this species has been poorly studied. The genetic diversity within and

D. Wan · A. Wang · G. Wu · C. Zhao $(\bowtie)$

MOE Key Laboratory of Arid and Grassland Ecology,

School of Life Sciences, Lanzhou University,

Lanzhou 730000, China

e-mail: zhaochm@1zu.edu.cn between populations undoubtedly is essential for designing conservation grams. In this study, we aimed to develop microsatellite primers for this endangered species.

We used DNeasy ${ }^{\mathrm{TM}}$ Tissue Kit (Qiagen) to extract the total genomic DNA from the silica gel using dried leaves. The microsatellite regions were isolated following Zhang et al. (2007). About $500 \mathrm{ng}$ genomic DNA was digested into approximately $500 \mathrm{bp}$ fragments with restriction enzymes $R s a \mathrm{I}(\mathrm{NEB})$ and XmnI (NEB), then ligated to SuperSNX24 double-stranded adaptors (mixation of equal volumes of equal molar amounts of SuperSNX24-F: 5'-GTTTAAGG CCTAGCTAGCAGAATC- $3^{\prime}+$ SuperSNX24 + 4P-R: $5^{\prime}$ GATTCTGCTAGCTAGGCCTTAAACAAAA-3'). For the further enrichment, the ligation products were hybridized with an oligonucleotide combination of $5^{\prime}$-biotinylated probes: $(\mathrm{AG})_{15},(\mathrm{CT})_{15},(\mathrm{AC})_{15},(\mathrm{GT})_{15},(\mathrm{CG})_{15}$, and $(\mathrm{CCA})_{15}$. The hybridization in the $50 \mu \mathrm{l}$ solution $(2 \times \mathrm{SSC}$, $1 \mu \mathrm{mol} / \mathrm{l}$ probe and $10 \mu \mathrm{l}$ ligation products) following the protocol: an initial $5 \mathrm{~min}$ at $95^{\circ} \mathrm{C}$, then a rapid cooling to $70^{\circ} \mathrm{C}$ followed by $0.2^{\circ} \mathrm{C}$ incremental decreases every $5 \mathrm{~s}$ for 99 cycles, and maintenance at $50^{\circ} \mathrm{C}$ for $10 \mathrm{~min}$; then decreases of $0.5^{\circ} \mathrm{C}$ every $5 \mathrm{~s}$ for 20 cycles, and finally rapid cooling to $15^{\circ} \mathrm{C}$. The DNA hybridized to the probe was captured by streptavidin-coated magnetic beads at $37^{\circ} \mathrm{C}$ for $1 \mathrm{~h}$ and then washed by the solution I $(2 \times \mathrm{SSC}$, $0.1 \%$ SDS $)$ and solution II $(1 \times$ SSC, $0.1 \%$ SDS $)$. The captured DNA was recovered by polymerase chain reactions (PCR) with SuperSNX-F (5'-GTTTAAGGCCTAGCTAG CAGAATC-3') and PCR product was purified with TIANquick Midi Purification Kit (TIANGEN). These fragments enriched with microsatellite loci were cloned using pMD18-T vector (TakaRa) and transformed into the E. coli competent cell (JM109, TakaRa). Positive colonies were amplified using BcaBEST $^{\mathrm{TM}}$ Sequencing Primers RV-M and M13-47. PCR products of 300-600 bp were 
sequenced using 3130xl Genetic Analyzer. The sequences containing motifs repeating more than 5 times were regarded as microsatellites. A total of 29 sequences were identified among the sequenced 200 sequences and primer pairs for amplification of the microsatellite regions were designed using the Primer 5.0 (Clarke and Gorley 2001).

In order to check polymorphisms of the identified microsatellite loci, 17 individuals from distantly distributed populations were selected for test. The PCR reactions were performed in $25 \mu \mathrm{l}$ reaction mixtures with $10-40 \mathrm{ng}$ template DNA, containing $19 \mu \mathrm{l}$ of sterile double distilled water; $2.5 \mu \mathrm{l}$ of $10 \times$ Taq polymerase reaction buffer; $1 \mu \mathrm{l}$ each of the primers; 1 unit TaqDNA polymerase. The amplifications used an initial denaturation of $5 \mathrm{~min}$ at $94^{\circ} \mathrm{C}$, and then followed by 38 cycles of $94^{\circ} \mathrm{C}$ for $40 \mathrm{~s}$, annealing for $40 \mathrm{~s}$ at $50-55^{\circ} \mathrm{C}, 72^{\circ} \mathrm{C}$ for $45 \mathrm{~s}$ plus a final extension of $72^{\circ} \mathrm{C}$ for $10 \mathrm{~min}$. PCR products were initially checked for PCR amplification on $2.0 \%$ agarose gels. The successful PCR products were further separated through $6.5 \%$ polyacrylamide denaturing gels. Allele sizes were compared with a 50 bp DNA ladder (TakaRa) and visualized by silver staining.

Allelic/genotypic frequencies were analyzed using GENEPOP version 3.4 (http://wbiomed.curtin.edu.au/ genepop/) (Raymond and Rousset 1995) to estimate observed and expected heterozygosity $\left(H_{\mathrm{o}}\right.$ and $\left.H_{\mathrm{E}}\right)$. Twelve loci of the 29 sequences showed polymorphic banding patterns and the other 17 comprised a single locus (Table 1). These loci had 3-12 alleles per locus and the observed heterozygosity and expected heterozygosity ranged from 0.1652 to 0.3183 and from 0.2929 to 0.4947 , respectively. For each locus, the expected heterozygosity was always significantly bigger than the observed heterozygosity $(P<0.05)$. No significant genotypic disequilibrium was detected for any pair of loci. As shown in Table 1, the sizes of the PCR products of these alleles range exceeding $20 \mathrm{bp}$ in most of 12 microsatellite loci and the alleles were sequenced and verified to be the target sequence.

The developed 12 loci in this study display successful amplification, reliable scoring and highly polymorphism

Table 1 Characteristics of 12 polymorphic microsatellite loci for $P$. tangutica

\begin{tabular}{|c|c|c|c|c|c|c|c|c|c|}
\hline Locus & Primers sequence $\left(5^{\prime}-3^{\prime}\right)$ & Repeat motif & $T_{\mathrm{a}}\left({ }^{\circ} \mathrm{C}\right)$ & $N$ & size range (bp) & $\begin{array}{l}\text { No. of } \\
\text { alleles }\end{array}$ & $H_{\mathrm{o}}$ & $H_{\mathrm{E}}$ & $\begin{array}{l}\text { GenBank } \\
\text { accession no }\end{array}$ \\
\hline Pt01 & $\begin{array}{l}\text { F:CTGACTTTGCCTGAACG } \\
\text { R:GAATCCTCCAGCCAGTA }\end{array}$ & $(\mathrm{GA})_{5}$ & 50 & 17 & $82-107$ & 6 & 0.1652 & 0.2929 & EU123857 \\
\hline $\mathrm{Pt} 02$ & $\begin{array}{l}\text { F:ACAAGAAAGAGGGGATAGA } \\
\text { R:CCACCACCACGCTCTT }\end{array}$ & $(\mathrm{AG})_{17}$ & 50 & 17 & $127-163$ & 5 & 0.3183 & 0.4947 & EU123858 \\
\hline Pt03 & $\begin{array}{l}\text { F: TAGCAGAATCACTTGGTC } \\
\text { R: TTCACAGGGATACAAACAG }\end{array}$ & $(\mathrm{GT})_{8^{-}}(\mathrm{TG})_{5}$ & 52 & 17 & $125-205$ & 12 & 0.3115 & 0.4874 & EU123859 \\
\hline Pt04 & $\begin{array}{l}\text { F:CAGCCCCAAAGAACAA } \\
\text { R:GGGCTGCTTCAACTACAC }\end{array}$ & $(\mathrm{GT})_{10}$ & 50 & 16 & $130-142$ & 4 & 0.2714 & 0.4237 & EU123860 \\
\hline Pt05 & $\begin{array}{l}\text { F: CCCTTCCAAGTCACAAA } \\
\text { R: ATCGTCGTGAAACAAACAT }\end{array}$ & $(\mathrm{TC})_{8}$ & 50 & 17 & $105-125$ & 3 & 0.2241 & 0.3742 & EU123861 \\
\hline Pt06 & $\begin{array}{l}\text { F: ACAATGTTTTGCGATAGAC } \\
\text { R: CACCAGTAGTGATTATGCT }\end{array}$ & $(\mathrm{AC})_{8}$ & 52 & 17 & $142-187$ & 6 & 0.1661 & 0.2980 & EU123862 \\
\hline $\mathrm{Pt} 07$ & $\begin{array}{l}\text { F: AACTACGCTCTCTGATCCT } \\
\text { R: TTCTTGGTTCACTGTTCTC }\end{array}$ & $(\mathrm{CCA})_{5}$ & 55 & 17 & $110-126$ & 5 & 0.2161 & 0.3325 & EU123863 \\
\hline Pt08 & $\begin{array}{l}\text { F: TCTTCCTGCAACTTATACAC } \\
\text { R: CAGGAAACAGCTATGACC }\end{array}$ & $(\mathrm{TC})_{8}$ & 55 & 15 & $102-132$ & 8 & 0.2549 & 0.4125 & EU123864 \\
\hline Pt09 & $\begin{array}{l}\text { F: GGCCTAGCTAGCAGAATC } \\
\text { R: TCTTAACAGAGCAACCATG }\end{array}$ & $(\mathrm{TG})_{5}$ & 50 & 17 & $182-196$ & 4 & 0.2549 & 0.4181 & EU123865 \\
\hline Pt10 & $\begin{array}{l}\text { F: GCTGCTGACATAGTTCCG } \\
\text { R: GTCAATAGAGTTTATTGCA }\end{array}$ & $(\mathrm{TC})_{8}(\mathrm{CT})_{5}(\mathrm{CT})_{9}(\mathrm{TC})_{9}$ & 55 & 17 & $209-176$ & 10 & 0.2780 & 0.4086 & EU123866 \\
\hline Pt11 & $\begin{array}{l}\text { F: CCTACTGTCGCAACCC } \\
\text { R: AATGACGACGAGGTGC }\end{array}$ & $(\mathrm{AG})_{5}$ & 50 & 15 & $95-110$ & 6 & 0.2618 & 0.4116 & EU123867 \\
\hline Pt12 & $\begin{array}{l}\text { F: GAATCGTTTCCACAATACA } \\
\text { R: AAATGACCTGTCCAAGAG }\end{array}$ & $(\mathrm{TC})_{10}$ & 50 & 17 & $140-172$ & 9 & 0.2360 & 0.3950 & EU123868 \\
\hline
\end{tabular}

The number of repeats is based on the sequence of the cloned alleles.

$T_{\mathrm{a}}$, annealing temperature; $N$, number of individuals genotyped; $H_{\mathrm{o}}$, observed heterozygosity; $H_{\mathrm{E}}$, expected heterozygosity 
levels. This set of loci will be useful in the studies of population genetics of $P$. tangutica.

Acknowledgments Support for this research was provided by the Education Ministry (FANDE2003027). The authors thank Prof. Liu Jianquan for helping to improve the language.

\section{References}

Clarke KR, Gorley RN (2001) PRIMER v5: user manual/tutorial. PRIMER-E Ltd., Plymouth, p 91

Pei GX, Li YH (1982) Przewalskia tangutica-a tropane alkaloidcontaining plant. Planta Med 45(6):112-115
Raymond M, Rousset F (1995) GENEPOP (version 3.4): population genetics software for exact tests and ecumenicism. J Hered 86:248-249

Wang H, Pan L, Zhang XF (2002) Quantitative analysis of three kinds of tropane alkalids in Hyoscyamus niger L. and Przewalskia tangutica Maxim. by HPLC. Northwest Pharm J 17(1):9-10

Yang YC (ed) (1991) Tibetan medicines. Qinghai People Press, Qinghai

Yang DZ, Zhang ZY, Lu AM, Sun K, Liu JQ (2002) Floral organogenesis and develpoment of two taxa in tribe Hyoscyameae (Solanaceae)-Przewalskia tangutica and Hyoscyamus niger. Acta Bot Sin 44(8):889-894

Zhang DY, Chen N, Yang YZ, Zhang Q, Liu JQ (2007) Development of 10 microsatellite loci for Rheum tanguticum (Polygonaceae). Conserv Genet 8. doi:10.1007/s10592-007-9344-9 